\title{
High dependency units in the UK: variable size, variable character, few in number
}

\author{
Fiona-Jane Thompson, Mervyn Singer
}

\begin{abstract}
Summary
An exploratory descriptive survey was conducted to determine the size and character of high dependency units (HDUs) in the UK. A telephone survey and subsequent postal questionnaire was sent to the 39 general HDUs in the UK determined by a recent survey from the Royal College of Anaesthetists; replies were received from 28. Most HDUs $(82 \%, n=23)$ were geographically distinct from the intensive care unit and varied in size from three to 13 beds, although only $64 \% \quad(n=18)$ reported that all beds were currently open. Nurse: patient ratios were at least 1:3. Fifty per cent of units had one or more designated consultants in charge, although only $11 \%(n=3)$ had specifically designated consultant sessions. Junior medical cover was provided mainly by the on-call speciality team. Twenty units acted as a step-down facility for discharged intensive care unit patients and 21 offered a step-up facility for patients from general wards. Provision of facilities and levels of monitoring varied between these units. Few HDUs exist in the $U K$ and they are variable in size and in the facilities and monitoring procedures which they provide. Future studies are urgently required to determine costeffectiveness and outcome benefit of this intermediate care facility.
\end{abstract}

Keywords: dependency, intensive care, high

Bloomsbury Institute of Intensive Care

Medicine, Department of Medicine,

University College

London Medical

School, London, UK

F-J Thompson

$M$ Singer

Correspondence to

Dr Mervyn Singer,

Bloomsbury Institute of

Intensive Care Medicine,

Department of Medicine,

UCL Medical School, Rayne

Institute Building,

University Street, London

WCIE 6JJ, UK

Accepted 30 November 1994

\section{Introduction}

Britain differs from mainland Europe in that it has fewer intensive care beds per 100000 population. ${ }^{1}$ As a consequence, a higher proportion of intensive care patients in the UK require mechanical ventilation and, by implication, more acutely ill, though non-ventilated patients are managed in non-intensive care ward areas. An intermediate care area, such as a high dependency unit (HDU), would therefore be beneficial for many of these patients.

An HDU is defined by the Association of Anaesthetists of Great Britain and Ireland ${ }^{2}$ as 'an area for patients who require more intensive observation, treatment and nursing care than can be provided on a general ward. It would not normally accept patients requiring mechanical dependency care

ventilation, but could manage those receiving invasive monitoring'.

A 1988 survey $^{3}$ from the Association of Anaesthetists identified only 55 hospitals in the UK with HDU facilities. However, a more recent audit ${ }^{4}$ identified that only 39 of 256 hospitals now have a designated HDU. We recently published a study ${ }^{1}$ costing intensive care and high dependency care in our hospital. Our case mix and levels of monitoring and staffing may significantly differ from general HDUs in other hospitals, thus making meaningful comparison difficult. We therefore undertook a survey to determine the size and character of HDUs identified by the recent report. $^{4}$

\section{Methods}

The 39 units identified by the Royal College of Anaesthetists Audit ${ }^{4}$ were provided by the author (J Stoddart, personal communication). A telephone survey was conducted to confirm their current existence, identify any other HDUs within the hospitals and to ascertain the named consultant in charge of each unit to whom a questionnaire would be sent.

A postal questionnaire comprising 32 closed questions was sent. Two weeks were provided for questionnaire completion and all nonrespondents were contacted with a follow-up postal questionnaire. The total duration of data collection was six weeks. A second telephone survey was conducted after the initial data analysis to clarify any points of ambiguity.

\section{Results}

From the initial telephone survey six of the previous 39 HDUs identified were now closed due to budgetary constraints. The total number of HDUs was 37 from a total of 33 hospitals, since two hospitals were subsequently identified as having more than one HDU facility. The response rate for completed questionnaires was $76 \%$ providing information on 28 HDUs in 26 hospitals. The geographical locations of these hospitals were as follows: London $(n=6)$, South England $(n=2)$, North England $(n=11)$, Scotland $(n=3)$, Wales $(n=3)$ and Northern Ireland $(n=1)$. The type and size of each responding hospital is shown in figure 1 and other specialist units is identified within the hospitals are displayed in table 1.

Most HDUs ( $82 \%, n=23$ ) were geographically distinct from the intensive care unit 


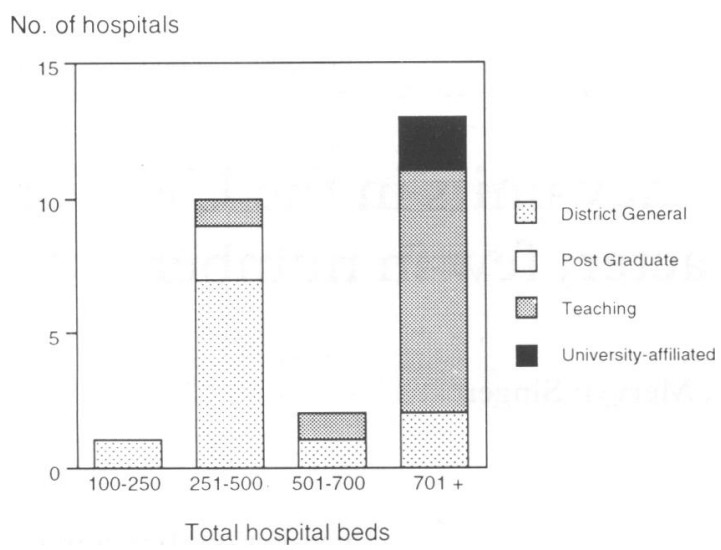

Figure 1 Type and size of responding hospitals

and $39 \%(n=11)$ of these units were part of an acute general ward. Figure 2 shows the number of beds designated for high dependency care. Sixty four per cent $(n=18)$ of HDUs reported that their total number of designated beds were currently fully staffed for high dependency care. Fourteen $(78 \%$ ) of the 22 fully open units had four beds or less while the six $(21 \%)$ units with closed beds ranged in size from 4-12 beds (median 8); 2-4 beds (median 2.5) were currently closed due to budgetary constraints.

\section{STAFFING}

Nurse:patient ratios were at least 1:3 although the smaller units (four beds or less) had proportionally more nurses. Only $50 \%(n=14)$ of these units reported having one or more designated consultants in charge, namely: surgeon $21 \%(n=6)$, anaesthetist $18 \%(n=5)$, intensivist $11 \%(n=3)$, and physician $7 \%(n=2)$. However, only $11 \%(n=3)$ of these units had specifically designated consultant sessions.

Junior medical cover during weekday working hours (09.00-17.00), was mainly provided by the speciality under which the patient was admitted $(85 \%, n=24)$ or by the intensive care unit or designated HDU team $(15 \%, n=4)$. Similarly, junior doctor cover at nights and weekends was provided by the on-call speciality team in $75 \%(n=20)$ of HDUs. Treatment strategies were executed predominantly by the primary or on-call team of the speciality under which the patient was admitted.

\section{ADMISSIONS}

Twenty two (78\%) HDUs collected statistical data on their patient admissions. Figure 3 depicts the number of patients admitted to these HDUs in the last year; this includes

Table 1 Specialist units identified within the responding hospitals

\begin{tabular}{ll}
\hline Unit & $\begin{array}{l}\text { Number of hospitals } \\
\text { having unit (\%) }\end{array}$ \\
\hline Intensive care unit & $26(100)$ \\
Accident and emergency department & $23(88)$ \\
Coronary care unit & $23(88)$ \\
Post-operative recovery ward & $20(77)$ \\
Acute admission ward & $13(50)$ \\
Renal unit & $8(31)$ \\
\hline
\end{tabular}

No. of HDUs

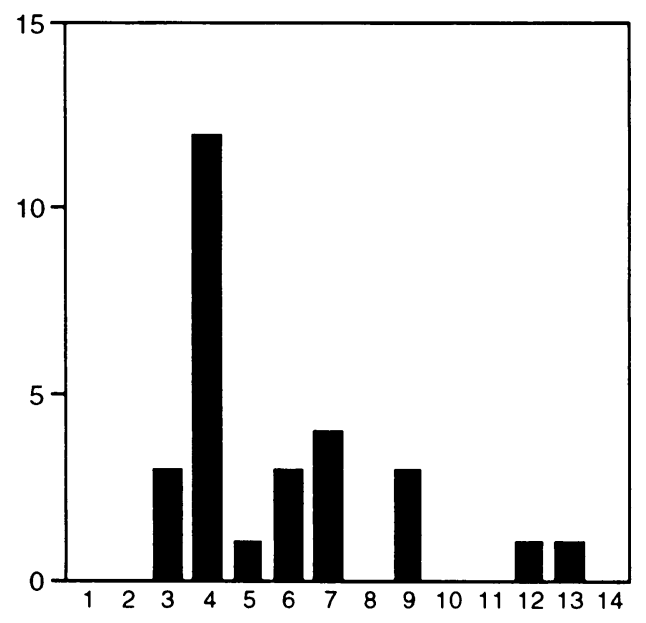

Number of beds in HDU

Figure 2 Number of designated beds per HDU

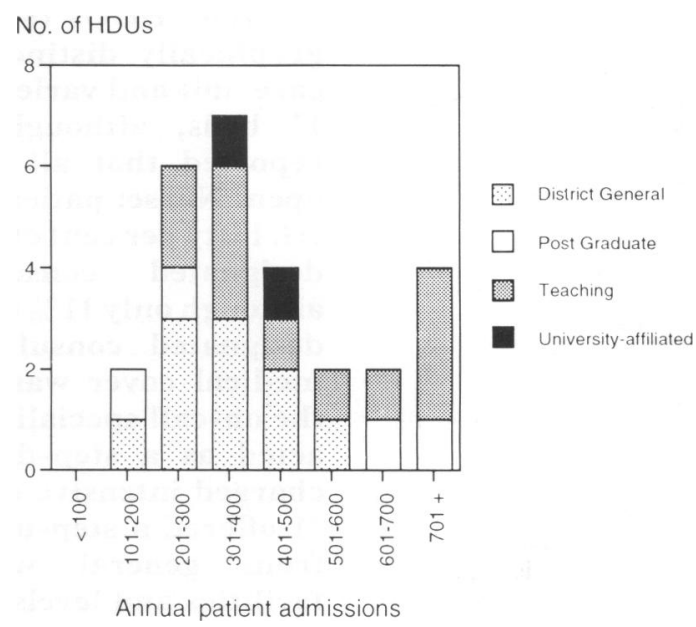

Figure 3 Annual patient throughput per HDU

estimations where statistics were not available. Very few units $(18 \%, n=5)$ utilised scoring systems for determining severity of illness, such as the Acute Physiology and Chronic Health Evaluation (APACHE) $\mathrm{II}^{5}$ and the Therapeutic Injury Severity Scoring (TISS) ${ }^{6}$ systems.

The majority of patient categories admitted to HDUs were classified as shown in table 2 .

The length of patient stay varied from 1.5 to 7 days (median 2.5). Twenty HDUs (71\%), reported that their HDU acted as both a 'step-down' facility for patients discharged from an intensive care unit and as a 'step-up' unit $(75 \%, n=21)$, for patients from general ward areas.

Fifty seven per cent $(n=16)$ of HDUs reported having an admission criteria policy. Although $50 \%(n=14)$ of HDUs stated that they had refused patient admissions in the last 12 months due to nursing staff and HDU bed shortages, these problems were sporadic.

Provision of facilities and monitoring procedures provided by these units and on general wards within their hospitals are shown in table 3. 
Table 2 Categories of patients admitted to HDUs

\begin{tabular}{lc}
\hline Category & Number $(\%)$ \\
\hline Post-operative elective & $20(74)$ \\
Post-operative emergency & $16(59)$ \\
Non-operative trauma & $16(59)$ \\
Medical (non-cardiac) & $14(52)$ \\
Medical (cardiac) & $10(37)$ \\
Burn injury & $5(19)$ \\
Paediatrics & $3(11)$ \\
\hline
\end{tabular}

Table 3 Provision of facilities/treatments in responding hospitals

\begin{tabular}{|c|c|c|}
\hline Facility/treatment & $\begin{array}{l}\text { Provision in HDUs } \\
(n=28)(\%)\end{array}$ & $\begin{array}{l}\text { Provision in general } \\
\text { wards }(n=26)(\%)\end{array}$ \\
\hline \multicolumn{3}{|l|}{ Monitoring } \\
\hline Intra-arterial pressure & $20(71)$ & $0(0)$ \\
\hline Pulmonary artery catheter & $12(43)$ & $0(0)$ \\
\hline Central venous pressure & $27(96)$ & $13(50)$ \\
\hline Pulse oximetry & $26(93)$ & $11(42)$ \\
\hline Continuous ECG & $28(100)$ & unknown \\
\hline \multicolumn{3}{|l|}{ Respiratory support } \\
\hline Mechanical ventilation & $3(11)$ & $0(0)$ \\
\hline Nasal positive pressure ventilation & $3(32)$ & $0(0)$ \\
\hline $\begin{array}{l}\text { Facial continuous positive } \\
\text { airways pressure }\end{array}$ & $16(57)$ & $1(4)$ \\
\hline Tracheostomy & $22(78)$ & $10(28)$ \\
\hline \multicolumn{3}{|l|}{ Cardiovascular support } \\
\hline Vasodilator infusion(s) & $23(82)$ & $6(23)$ \\
\hline Inotropes & $23(82)$ & $6(23)$ \\
\hline Cardioversion & $11(39)$ & $1(4)$ \\
\hline Pacing & $11(39)$ & $3(12)$ \\
\hline Intra aortic balloon pump & $1(4)$ & $0(0)$ \\
\hline \multicolumn{3}{|l|}{ Renal support } \\
\hline Haemofiltration & $6(21)$ & $0(0)$ \\
\hline Haemodialysis & $4(14)$ & $0(0)$ \\
\hline Peritoneal dialysis & $6(21)$ & $3(12)$ \\
\hline Plasma exchange & $1(4)$ & $0(0)$ \\
\hline \multicolumn{3}{|l|}{ Analgesia/sedation } \\
\hline Epidural analgesia & $20(71)$ & $7(27)$ \\
\hline Patient-controlled analgesia & $24(86)$ & $15(58)$ \\
\hline Continuous intravenous sedation & $20(71)$ & $7(27)$ \\
\hline
\end{tabular}

\section{Discussion}

Despite the relative paucity of intensive care beds compared to mainland Europe, few HDU resources currently exist in the UK. There is also a wide variation in facilities, procedures and medical cover which the HDUs provide. In spite of recommendations for the provision of HDUs, ${ }^{2}$ there has, in fact, been a decrease in the availability of these facilities. This may prove to be a false economy since the HDU may '. . . provide the appropriate care for many acutely ill patients who do not require the full facilities of an intensive care unit'. ${ }^{2}$ Thus, the HDU may offer a step-up facility for a patient whose condition gives cause for concern, where greater monitoring and supervision may prevent the need for admission to intensive care which may prove considerably more lengthy and expensive. Conversely, the HDU could act as a step-down unit for patients who no longer require intensive care, but who are not ideally suited to return to a general ward.
Less than $10 \%$ of patients in a study at University College Hospital ${ }^{1}$ required a stepup from HDU to intensive care. The high proportion of intensive care patients who are mechanically ventilated $(80 \%)$ and haemofiltered $(21 \%)$ suggests more effective utilisation of intensive care facilities. Thus, intensive care units with less than $50 \%$ of their patients being ventilated may benefit from having more HDU beds and fewer intensive care beds. The total cost of an intensive care patient day in 1991 on the University College Hospital unit was $£ 1148.72$ in contrast to $£ 437.68$ for an HDU patient day.

Readmission rates to intensive care units are shown in table 4 . It is noteworthy that the University College Hospital patient readmission rate was half that of the others quoted ${ }^{7,8}$; whether or not the presence of an HDU at this hospital was a significant factor requires further study though there can be no denying the higher subsequent morbidity and mortality of patients requiring readmission (box 1 ). ${ }^{9}$

Rowan et $a l^{10}$ also identified that $17.9 \%$ of UK intensive care unit admissions died in the unit while a further $9.8 \%$ died in hospital after discharge from the unit. Bion ${ }^{11}$ questioned why these patients were dying on the wards and suggested one or more of the following possibilities: premature discharge from the intensive care unit due to pressure on beds, lack of high dependency facilities and inappropriate admission to intensive care. However, no data yet exist to answer this question. The National Confidential Enquiry into Perioperative Deaths (NCEPOD: 1991/1992) ${ }^{12}$ in the UK provided some national data on postoperative deaths (box 2). How many of these deaths could have been prevented by an HDU facility is also open to question.

A 'snapshot' study ${ }^{14}$ of the subjective dependency of postoperative surgical patients in eight UK hospitals suggested that up to $13.5 \%$ of general ward patients would have

Table 4 Readmission rates to intensive care units (ICUs)

\begin{tabular}{lcc}
\hline Study and site & $\begin{array}{l}\text { Total ICU } \\
\text { admissions }\end{array}$ & $\begin{array}{l}\text { Readmissions } \\
(\%)\end{array}$ \\
\hline $\mathrm{UCH}^{1}$ & 114 & $3(2.6 \%)$ \\
$26 \mathrm{UK} \mathrm{ICUs}^{7}$ & 8786 & $460(5.2 \%)$ \\
$13 \mathrm{US} \mathrm{ICUs}^{8}$ & 17440 & $818(4.7 \%)$ \\
\hline
\end{tabular}

\section{Characteristics of patients} requiring readmission to intensive care?

- mortality $41.5^{\circ}$ o (vs $7.3^{\circ}$ in control ICU patients matched for age, sex, primary disease)

- mean length of stay $47.8 \pm 42$ days ( $v s$ $20.8 \pm 14.2$ days in control patients)

- $54 \%$ of readmissions had respiratory failure

- $30^{\circ} \%$ of readmissions had recurrence or worsening of original problem 


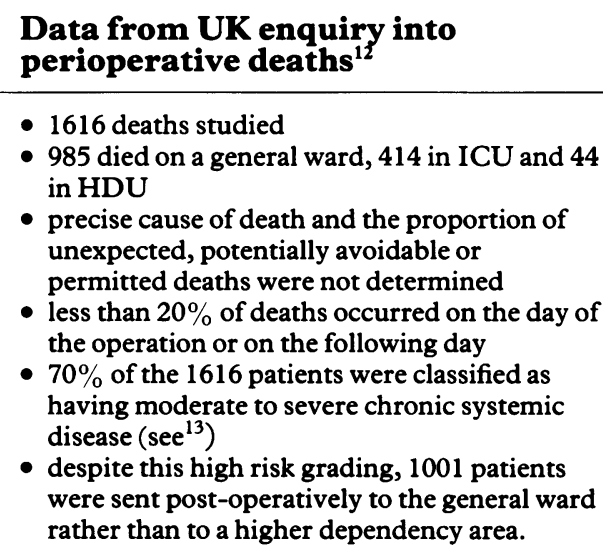

- 1616 deaths studied

- 985 died on a general ward, 414 in ICU and 44 in HDU

- precise cause of death and the proportion of unexpected, potentially avoidable or permitted deaths were not determined

- less than $20 \%$ of deaths occurred on the day of the operation or on the following day

- $70 \%$ of the 1616 patients were classified as having moderate to severe chronic systemic disease (see ${ }^{13}$ )

- despite this high risk grading, 1001 patients were sent post-operatively to the general ward rather than to a higher dependency area.

Box 2

been appropriate for HDU care, while approximately $50 \%$ had inappropriately placed intensive care unit patients. However no data on outcome was provided. Kilpatrick et $a l^{15}$ also found that $40 \%$ of their intensive care unit admissions had a low calculated and actual risk of hospital mortality. Many were admitted with metabolic disorders, post trauma and for respiratory observation and monitoring. The authors suggested that these patients may be more appropriately managed on an HDU.

The American College of Physicians conducted a Clinical Efficacy Assessment Project $(\mathrm{CEAP})^{16}$ to ascertain from published data whether it was possible to identify patients unlikely to benefit from intensive care before admission to an intensive care unit and to subsequently treat them in a step-down (intermediate care) area. Patients considered unlikely to benefit from intensive care in the study were either low risk monitored patients or high risk patients who die despite aggressive therapy. However, they were unable to find any data as studies identified these patients after admission to the intensive care unit rather than before. Thus, they shifted the emphasis of their study to find, within the first 24 hours of intensive care unit admission, those patients who could be managed in a less resourceintensive environment without having a negative effect on outcome. Again, no studies were found so they recommended a multicentre study should be performed to determine outcomes on patients identified as low risk who are randomly assigned to alternative hospital locations for treatment compared with those assigned to continued intensive care unit treatment until routine discharge.

A further justification for HDU facilities arises from the recent initiative to reduce junior doctors' working hours. This has resulted in decreased cover at nights and weekends so concentration of sicker patients in a better staffed and monitored area may be advantageous. Nurse practitioners ${ }^{17}$ with higher levels of training may possibly have a useful role in this area.

No data exist on the cost-effectiveness of high dependency care. Obviously, meaningful

\section{Learning/summary points}

- the HDU is an intermediate care facility between the general ward and intensive care unit, offering both step-up and step-down functions

- few HDUs exist in the UK

- those that do vary in size (3-13 beds), patient throughput, and monitoring and treatment capability

- the majority of HDU beds are used for post-operative care

- though $50 \%$ of HDUs have designated consultants in charge, few have dedicated consultant sessions

- studies have yet to be performed to determine whether the HDU is both cost-effective and beneficial in terms of patient outcome

Box 3

comparison between different hospitals would be difficult in view of the wide variation in their character and the facilities provided. However, such a study is urgently needed because of ever increasing financial restraints and limitation of resources. In a study conducted in two British District General Hospitals in 1988, Shiell et al ${ }^{18}$ estimated costs of $£ 525$ and $£ 465$ per intensive care unit patient day. At University College Hospital in $1988^{1}$ our equivalent costs were $£ 779$ for an intensive care unit patient day and $£ 163$ for an HDU patient day, with an average cost of $£ 327$ for a combined intensive care unit/HDU patient day. This is considerably cheaper than for the two hospitals above which had a median APACHE II score on admission of 11 in contrast to a 24-hour APACHE II score of 18 in our intensive care unit.

In an attempt to limit costs and relieve pressure on intensive care beds in the US, the development of intermediate care facilities have been advanced. A 1985 national sample of US intensive care units ${ }^{19}$ revealed that $10-50 \%$ of patients were not considered to have received active intensive care. Oye and Bellamy ${ }^{20}$ claimed that $41 \%$ of admissions to their medical intensive care unit did not receive acute treatments and that these 'monitored' patients had a $99 \%$ intensive care unit survival and $90 \%$ hospital survival. In 1988 Wargovich et $a l^{21}$ found that a third of all designated intensive care unit beds in the state of New Jersey were now staffed and equipped as intermediate care areas. Many of the patients currently admitted to intensive care units in the UK appear to fall into this category and thus could be cared for in a high dependency setting.

In conclusion, HDU facilities are generally lacking in the UK. Proper utilisation of this resource could have significant implications on outcome and benefit. Studies of costeffectiveness and outcome benefit are urgently needed to validate this.

The authors would like to thank Dr JC Stoddart, Royal Victoria Infirmary, Newcastle upon Tyne for supplying the list of 39 HDUs, and the 28 HDUs who completed the questionnaire. 
1 Singer M, Myers S, Hall G, Cohen SL, Armstrong RF. The cost of intensive care: a comparison on one unit between 1988 and 1991. Intensive Care Med 1994; 20: 542-9.

2 The Association of Anaesthetists of Great Britain and Ireland. The High Dependency Unit-acute care in the future. London: Association of Anaesthetists, 1991.

3 The Association of Anaesthetists of Great Britain and Ireland. Intensive Care Services-provision for the future. London: Association of Anaesthetists of Great Britain and Ireland, 1988.

4 The Royal College of Anaesthetists. National ITU Audit. London: Royal College of Anaesthetists, 1992/1993.

5 Knaus WA, Draper EA, Wagner DP, Zimmerman JE APACHE II: a severity of disease classification system. Crit Care Med 1985; 13: 818-29.

6 Keene AR, Cullen DJ. Therapeutic Intervention Scoring System: update 1983. Crit Care Med 1983; 11: 1-3.

7 Rowan KM. Outcome comparisons of intensive care units in Gowan KM. Outcome comparisons of intensive care units in Great Britain and Ireland using the APA

8 Knaus WA, Wagner DP, Zimmerman JE, Draper EA Variations in mortality and length of stay in intensive care units. Ann Intern Med 1993; 118: 753-61.

9 Durbin CG, Kopel RF. A case-control study of patients readmitted to the intensive care unit. Crit Care Med 1993; 21: $1547-53$.

10 Rowan KM, Kerr JH, McPherson K, Short A, Vessey MP. Intensive Care Society's APACHE II study in Britain and Ireland-II: outcomes comparisons of intensive care units after adjustment for case mix by the American APACHE II method. BMF 1993; 307: 977-81.
11 Bion J. Outcomes in intensive care - are related to skill mix, bion Je Outcomes in intensive care - are related to skill mix, b53-4.

12 Campling EA, Devlin HB, Hoile RW, Lunn JN. The report of the national confidential enquiry into perioperative deaths 1991/1992. London, 1993.

13 American Society of Anesthesiologists: New classification of physical status. Anesthesiology 1963; 24: 111-3.

14 Crosby DL, Rees GA. Provision of postoperative care in UK hospitals. Ann R Coll Surg Engl 1994; 76: 14-8.

15 Kilpatrick A, Ridley S, Plenderleith $\mathrm{L}$. A changing role for intensive therapy: is there a case for high dependency care? Anaesthesia 1994; 49: 666-70.

16 Bone RC, McElwee NE, Eubanks DH, Gluck EH. Analysis of indications for early discharge from the intensive care unit. Clinical Efficacy Assessment Project: American College of Physicians. Chest 1993; 104: 1812-7.

17 Mirr MP. Advanced clinical practice: a reconceptualized role. Clin Iss Crit Care 1993; 4: 599-602.

18 Shiell AM, Griffiths RD, Short AIK, Spiby J. An evaluation of the costs and outcome of adult intensive care in two units in the UK. Clin Intensive Care 1990; 1: 256-62.

19 Wagner DP, Knaus WA, Draper EA. Identification of low-risk monitor admissions to medical-surgical intensive care units. Chest 1987; 92: 523-30.

20 Oye RK, Bellamy PE. Patterns of resource consumption in medical intensive care. Chest 1991; 99: 685-9.

21 Wargovich RM, Bekes CE, Cernaianu A. Intermediate intensive care unit in New Jersey. Crit Care Med 1988; 16: 1167-8.

William Harvey (1578-1657) was born at Folkestone, where his father had a thriving business carrying mail and other items, initially throughout Kent and later across the English Channel. Young Harvey was a small man, sharp-eyed and of olive complexion. His broad head narrowed to a point at the chin, which bore a small beard beneath a thick moustache. A raised left eyebrow gave rise to a quizzical expression. His numerous idiosyncrasies included keeping sugar in his salt cellar, combing his hair while walking out of doors, fingering the dagger he always wore, and treating his own gout by putting his legs in a bucket of cold water and then roasting in front of a fire. He was addicted to that new beverage, coffee.

He was educated at King's School, Canterbury, Gonville and Caius College, Cambridge, Padua University and then became physician at St Bar-

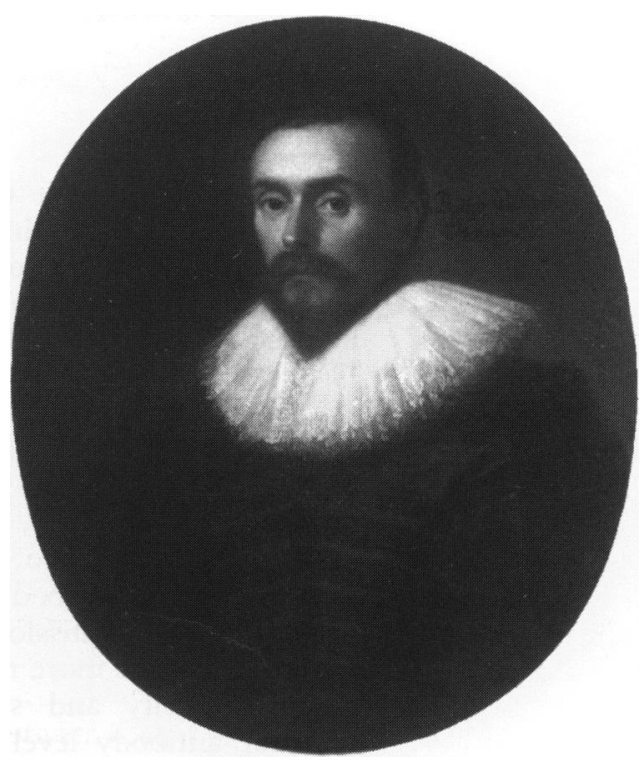

Courtesy of National Portrait Gallery

tholomew's Hospital. He wrote his immortal De motu cordis (1628) when he was aged 50. Until that time, the Galenic concept of the blood flow was of some slow drift of blood from the right to the left heart. Harvey argued that valves in veins must suggest an onward flow of a venous and arterial circulation and not ebb and flow like the tide.

William Harvey's discovery revolutionised the concept of the circulation of the blood with its constant irrigation of the tissues by a vast network of blood vessels, ranging from the main artery with a calibre of two thumbs down to the finest capillaries with a diameter of one-tenth of a human hair. The aggregate length of this complex system of vessels is thousands of miles, and yet it is filled with less than six litres of blood.

Harvey died on June 3, 1657 in Roehampton and is buried at the Church of St Andrew, Hempstead, Essex. 